\title{
Employee Engagement in Times of Crisis
}

\author{
Manali Rohan Patil and Pranali Rana \\ Assistant Professor - HR, PTVA's Institute of Management \\ Student, PTVA's Institute of Management Maharashtra India
}

\section{ABSTRACT}

limited to employee productivity then on we graduated to shifting our focus to correlating performance with employee satisfaction. Higher the levels of employee satisfaction, greater the performance. Of late with the changes in nature of businesses we have started realizing and talking about the most critical and neglected aspect known as "employee engagement". Engagement is often said as a capture of an employee's head and heart. Today the world is different than it used to be nearly a year ago. The global pandemic has caused an atmosphere of uncertainties and confusion creating communication gaps and lead to complete disruption in our lives. In such a scenario, keeping employees engaged and passionate about work is a challenge ahead of organizations worldwide. This paper attempts to focus on studying the impact the global pandemic has on various employee engagement practices and strategies of the firms. The primary purpose of this research is to understand how such periods of crisis impacts the employee engagement practices and to be more specific which areas of employee engagement has changed drastically during this crisis. Employee engagement in such trying times assumes a paramount importance. Though a lot of organizations have encountered a plethora of challenges due to Covid -19 crisis in adjusting their management styles and working practices it is a question unanswered as to how the lessons learned about the employee engagement will be brought to practice in their working model. It will surely bring scope for positive improvements and shift in area of focus in employee engagement practices in the organizations in years to come.

\section{KEY WORDS: EMPLOYEE ENGAGEMENT, CRISIS, UNCERTAINTIES, CORPORATE CULTURE.}

\section{INTRODUCTION}

Let us try and understand the mindset of an engaged employee - a highly engaged employee right in the morning would be energetic, enthusiastic, more willing to work, would be passionate about his work, one who knows what he/she is supposed to do, someone who really looks beyond the daily tasks, these are not mere adjectives but the reality of what really happens with an

Biosc Biotech Res Comm P-ISSN: 0974-6455 E-ISSN: 2321-4007

\section{crosstef}

Identifiers and Pagination

Year: 2021 Vol: 14 No (5) Special Issue

Pages: 01-06

This is an open access article under Creative

Commons License Attribn 4.0 Intl (CC-BY).

DOI: $h t t p: / / d x$.doi.org/10.21786/bbrc/14.5/1 engaged employee each day, it isn't something he or she has received from a training nor anybody has asked him/ her to feel in this manner, these feelings and emotional wellbeing is achieved when an organization invests in an employee engaged culture, it isn't forced upon him or her but it comes naturally to such an employee. Having said that, lets also find out what a disengaged employee would feel like before heading to office each morning. They feel lethargy, apathy, most of the days they don't even feel like going to work, feels low on energy and lacks enthusiasm. These are like certain signs of a disengaged employee.

These negative flaws reflect on other people and if you don't address it swiftly, things could get worsen. That's the reason organizations today are investing in building engaged culture within an organization. Employees are, at their worst engulfed in ambiguity and chances are that this chaos can affect their mental well-being 
during this uncertain times. These unengaged employees feel detached and are distracted due to a lot of things happening around which surely affects their efficiency and performance.

The crux for engaging your employees lies in developing this understanding that whatever circumstances your organization or your team is going through there are chances that employees are likely to feel disengaged and lost, so how swiftly your organization develops this ability to connect and communicate to team members to leverage the effect of peer motivation on efficiency is more critical than it has ever been.

Literature Review: Chanana N. and Sangeeta (2020) attempted to determine the engagement practices adopted by various companies during the global pandemic times. During the time of crisis, employee engagement has become one of the important human resource activity concern as almost everyone was working from home, it was becoming extremely difficult to monitor employees output their concerns and also their productivity during such times.

Kaushik M. \&t Guleria N. (2020) has mentioned that during this tough times it becomes of an immense importance to maintain harmony and understanding in organizational relationship in order to businesses to sustain and grow further. It is time to develop positive approach and attitude towards everything in life not just at professional front. To lay emphasis on reskilling and upskilling. To accepting technological interventions and adapt to the change.

Kumar A. \&t Kapoor S. (2020) tries to outline various engagement measures/practices to increase the levels of employee engagement and also summarized that organizations must value mindful engagement. It studied the impact of two critical factors namely emotional well-being of the employees and the other one as using digital technology in use for engaging employees. On the final node, author proposes that when employer would be able to evaluate the emotional pattern and well-being levels of an employee and demonstrate empathy towards their concern it will led to a win-win situation to both the parties and help increase productivity even in such an uncertain times.

Saji B.S. (2014) has explained that by engaging employees' organization can reduce attrition of its employees. It describes as to how having an engaged and committed staff can save companies during the times of crisis with the help of Taj hotel, Mumbai, case study. It also laid emphasis on having learning and development system and through timely L\&D sessions, employees can be engaged even more.. Various HR practices from hiring, letd, reward and recognition together leads to higher levels of employee engagement.

Setyo Riyanto (2020) proposes to examine the effect of pandemic on employees personal and work life and that managing their concerns and emotions becomes critical else it may go on to result in poor quality of work, lower levels of productivity, mistakes and in all impacting business at large. These emotions if left unattended will surely influence employee performance and engagement levels. The researcher concluded by laying importance on the fact that employers needs to understand and empathize with concerns of the employees in such turbulent times is the best practice or simple way of keeping employees engaged.

\section{Objectives of the Study}

1. To determine employee engagement practices and strategies adopted during Covid-19 crisis by organizations.

2. To study which areas of employee engagement has changed due to pandemic .

3. To study the role of employee engagement in developing a strong corporate culture.

\section{RESEARCH METHODOLOGY}

For the purpose of this research, primary data was collected through a well-structured questionnaire and review of secondary data about the current crisis situation and employee engagement was done.

5.Data Collection: Questionnaire was administered via sharing the google form to randomly select regular office going employees (currently working from home). The questions in the engagement survey are directed towards an organization's employee to understand their level of engagement with the organization at large. These employees/professionals are working for leading organizations. Filling the complete responses was done through the Google forms circulated. The questionnaire was served to full time employees selected randomly from Mumbai.

\section{Strategies Adopted By Companies During Crisis} - Work from Home model adopted: Even from WFH model, through virtual space leaders and team members can still ensure that they celebrate on achievements of its employees. Even if this present situation has prompted a downturn and stagnation in your business affecting your profits and lead to restricted allocations on budgets. Appreciation and recognition factor doesn't have to be costly, complex, or even for that matter expensive.

It cannot be ignored for any reasons there's always a way out to it. It is free and very efficient to say "thank you" but do it in a significant manner like by acknowledging them by emailing or announcing it in a group meeting so that everyone else also comes to know about the same, and the one receiving such appreciation feels happy and motivated at the same time.. By giving them extra time off can be also another good idea generally in case if your teams are one that normally hits deadlines and meets targets. Employees in such conditions feel motivated and involved and this further awakens in them a sense of belonging and oneness. 
- Covid effect and how firms reacted to this change: Due to this global pandemic scenario, there is a lot of things that are out of control. Now, organizations need to be adaptive and resilient to the changes in order to sustain the business in times of crisis like these. There are a lot of skills and technology know-how that has become all the more imperative then it use to be before the Covid times. We are being used to working in an "all touch" environment before, where we had to be physically present but now due to pandemic everything moves on technology be it meetings, communications, collaborations, celebrations almost everything.

This is not the time of just performance but high performance now that will matter and make a differentiating factor to those firms. Today we need to understand about having work life balance and achieve harmony in both personal and professional lives by increasing productivity and efficiency, and that can be achieved by having focus on the sense of belongingness and integration of tasks and activities at workplace. In order to have a highly engaged workforce, employers need to understand the changed expectation of the employees in regards to feedback, recognitions, appreciation in this changing era Let's try to focus on how Covid -19 has affected employee engagement today.

Employee engagement is therefore core for organizations who are actually looking for ways to get out of this crisis. That said, employees are going to remember as to how you treated them at this time. Organization needs to be attentive about employees concerns and their mental well-being in such an uncertain time, which clearly depicts that organization is watchful, empathetic for its employees even in such tough times. The global pandemic has act as a catalyst in accelerating entire technological transformation that has taken place.

Having a culture of recognition also drives employee engagement. It is important for the organization to have a supportive management approach. During the lockdown scenario when employees where working from home various organizations adopted online methods such as daily team meetings, frequent check ins in order to monitor and keep track of employee's productivity and measure their progress and output. Organizations resorted to giving its employees small tasks and procedure and this approach of micro goal setting enabled them to receive constant feedback and helps in evading communication gap during turbulent times. When communication gap reduces it automatically facilitates resolving issues and concerns in no time, allowing time to anticipate things.

It requires strong effort and commitment from top management to adopt such an approach or model of supportive management in such trying times to foster and engage its employees to achieve results. In order for engaging employees during this tough times another critical aspect adopted by firms was to focus on to praise and recognition of employees at work. Praising employees and appreciating their efforts and their work goes a long way in keeping them engaged, regardless of the size of the company.

- Approaches adopted in engagement: Those leaders who invest in Learning \&t Development (LED) activities of its employees clearly shows an indication that they are encouraging engagement. LED is a critical element of employee engagement. L\&D activity itself is incomplete if it doesn't include constructive feedback in it and again not to forget two-way communication element, only then in true sense such an LCD can be said engaging. Having said that, these practices facilitate continuous communication and makes room for transparency within the organization, which helps develop a strong employee engagement model, that can help keep employees engaged and increase their retention to a great extent.

Various organizations across the world had adopted to stay connected using virtual platforms at all levels. There has been emphasis on two-way communication between leaders and employees. It not just leads to monitor employees' performance and productivity but also gives a sneak peek into employees' emotional state of mind. HR professionals needs to understand that due to work from home working model, employees might feel isolated and lonely, they should engage employees in virtual social activities to build camaraderie and offer some sort of mental relief to its employees and take care of their emotional well-being. HR team must work on developing a system for attending work related queries of its employees as simple as using computers camera and running an online meet. There should be FAQs document updated from time to time. Keeping employees updated about not just professional stuffs but also related to health care guidelines, mental well -being, etc.

- Drivers of employee engagement: At first we need to take another look at what are the drivers and motivations in order to better understand what approaches will prove to be active in convincing and influencing employee engagement. In their jobs, often employees can't seem to find any purpose any sense or even see the contribution their jobs makes. Think of the duties or tasks you carry out on a regular basis. It is important to see meaning in their work. Meaning is the first key that builds in employee engagement that lasts for long time.

It creates joy and happiness in an individual. In words of Daniel Pink, "Control leads to compliance; Autonomy leads to engagement." Autonomy isn't about leaving people alone. Typically, employees don't want to be left alone. It is not generally recommended to tell people about how to do things. To empower them and ask them about what to do and you will be surprise by the results. Autonomy does really allows an employee to practice a degree of self -governance. Coming to another driver, growth - for about a decades ago, it use to be so that an employee possessed and maintained a particular skillset and education these factors use to form base for his career and even so that it use to carry further throughout his professional life, leaving less or almost no scope of growth. 
Another important driver is impact - imagine a scenario wherein your employees give in their best efforts and in return they get a dismal report of their business performance, the plight and mindset of such an employee is sad and demotivated one. It becomes difficult in such a scenario to cultivate the engaged employee environment Connection - that feeling of oneness, belongingness often are included in various employee engagement survey questions. Because unless and until your employees don't really feel that connection, the spark in their work and output is surely going to suffer then. Connection does really makes an employee involved, included and part of the organization. Recognition and appreciation Recognition and appreciation goes a long way to keep employees engaged. Each and every employee is unique in itself we need to understand this fact and accordingly design and frame reward recognition policies that makes that individual employee feel better is of paramount importance.

- Building a strong corporate culture: Perks are becoming increasingly famous in corporate world. Perks, at least initially, are beneficial for recruitment and retention. All of these advantages, especially for the recent college graduate looking for a quick transition from school to work and bragging rights, look extremely attractive. Companies are becoming creative and extremely competitive day in and day out in introducing these perks for their employees such as allowing pets, free food, the onsite dentist, free medical check-ups policies, oil changes and this is going to be never ending for sure.

All these perks and such policies might seem like a fairly decent life to live like, isn't it? It's like everything that you would ever need can be taken care by your organization. The issue is the elevated cost of your entire life for this form of treatment. Let's try and understand the companies perspective also perhaps feels that why else would you really ought to leave? Employee may feel stuck and detached. So, the whole alignment of his efforts and output disturbs. Here, is where your employee engagement program goes for a toss, because despite of giving your employees those perks and amenities he feels disengaged and performances poor.

That's where your culture and internal management leader and management comes to picture. And here, let's dive into understanding the importance of building a strong corporate culture. Firms needs to understand this that, Perks are really not going to prove enough to help you with your engagement activities that is for sure . They can really help your employees feel satisfied but surely not engaged. You must be wondering how? Often, do firms forget to acknowledge the fact that there is something beyond those perks too. Instead they should look for broader picture rather beyond the picture and invest in cultivating such an environment which is rich with opportunities for ample growth of the employees, showing individuals how they have an impact, their actions and efforts matters to the organization, their works and their jobs have meanings, you as an organization needs to understand your employee, this aspects and then these efforts will indeed lead to real employee engagement and will help your organizations manifolds.

Often leaders feel that, doing engagement survey alone is sufficient and can help organizations improve, however it is partially correct. Improving overall culture is way more important and effective way to increase business profits and achieve success. Employee engagement is directly proportional to strong company culture. Having a strong corporate culture implies how well employees are aligned with the company's vision, mission, goals, strategies, etc. They better know what is expected of them, he or she is intrinsically motivated and has that positive approach and attitude towards working, etc. Employees today are expecting and visualizing such a corporate culture that in reality treats its employees as humans first, and this further promotes a work-life balance indeed! Today they demand and look forward to working in such a workplace that has this touch of personalization in it.

Each employee is a different being and so they should be treated that way. A short term substitute for an engaged purpose and Covid-19 has united us against a common enemy. I do believe that we are very much in a situation business wise that it is the calm before the storm as we move towards what people are talking about the new normal or for businesses the normal is never coming back. Talking about the crisis response so what the business does in response to the pressure of the crisis and how the leaders actually contribute to creating temporary engagement that characterizes the Covid trap.

\section{Data Analysis And Interpretation}

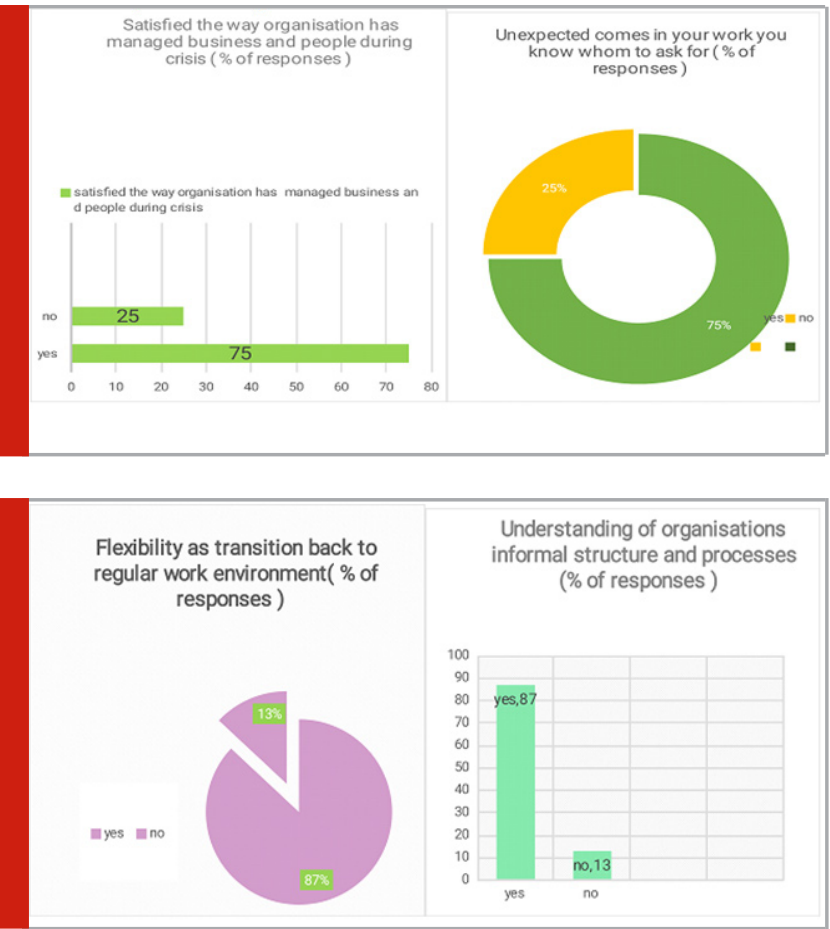



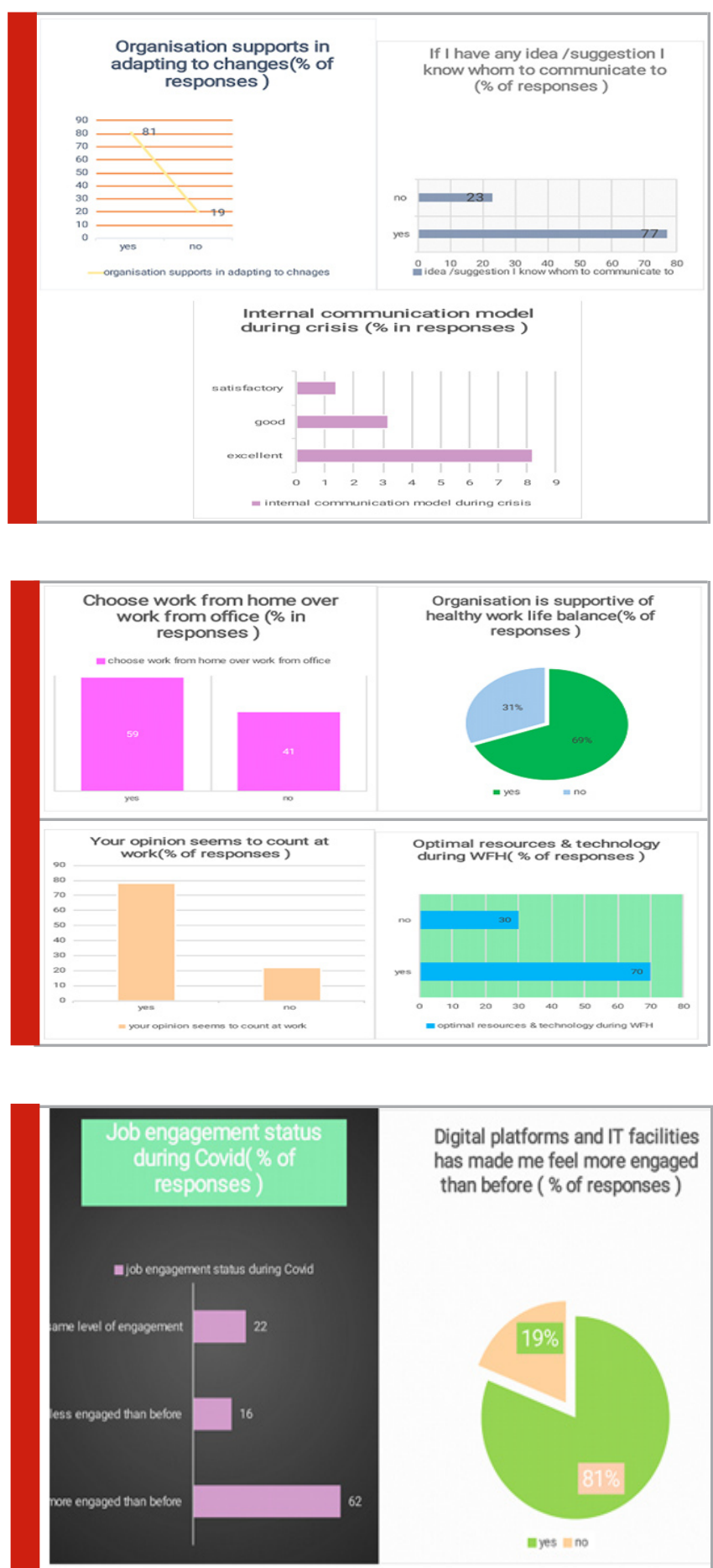

Digital platforms and IT facilities has made me feel more engaged than before ( $\%$ of responses )

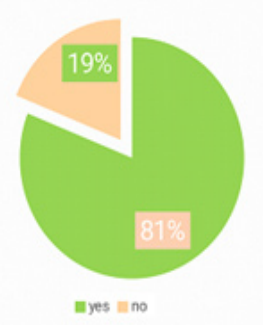

Emotional well-being has positive impact on job engagement during crisis times( $\%$ Of responses )

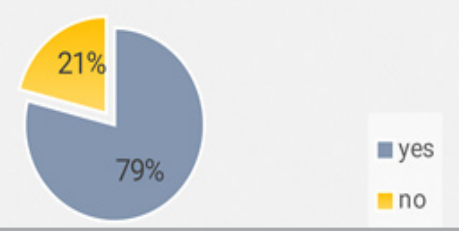

\section{Findings}

1. It was found that around $82 \%$ of respondents agreed that they love their work.

2. $78 \%$ of them agreed that they have positive and happy work environment.

3. $75 \%$ of them believed that they are satisfied with managed business and people and they know where to go when unexpected work comes our way.

4. $87 \%$ of them agreed to flexibility and understanding informal structures of organization.

5. $72 \%$ of them were satisfied with rewards and recognition policies.

6. $81 \%$ of them agreed that organization supports in adapting to changes.

7. $77 \%$ of them had this idea that they know whom to communicate an idea

8. $80 \%$ of them agreed with internal communication model during crisis

9. 59\% of them said that they will chose WFH over WFO model.

10. $69 \%$ of them said their organization supports healthy work life balance.

11. 79\% of the respondents said they emotional wellbeing has a positive impact on a job engagement during the crisis times.

\section{Suggestions and Recommendations}

- Empathize with your employees

- Engagement is for everyone - Organizations needs to capture the head, heart and souls of employees and instill in them this desire and passion towards work for excellence needs to strongly present in them

- Localize - in order for organizations to withstand and come out strong from this pandemic, they need to understand that employee engagement cannot be done from the corporate headquarters itself, because the time has changed and so has the demand. Companies from their end needs to ensure that they must engage locally by that it means local managers of the offices, of the divisions, departments, etc. will play a significant role and important factor in engaging employees from grass root level.

- Give autonomy, liberate employees - Companies in these turbulent times needs to give their employees liberty and autonomy to allow them to choose how to go about working further. Assign them tasks, but don't legislate, don't ask them how to do that, give them autonomy to choose to work according to their convenience and then see the results. It will surely, improve productivity and help in achieving success.

- Redefine Communication strategy- In a crisis situation, internal communication system model has an immense role to play and needs to reinforced again and again without forgetting the importance of feedback. Those organisations that have invested and paid more attention to internal PR than external PR has passed the test!

- Involve and include - It becomes important to involve your employees in decision making during crisis situation wherein, every small decision and discussion matters. Through regular Zoom calls and 
Google hangouts, companies can ensure that their employees are involved in discussions and so they feel included too, this instills in them the feeling of oneness and engages them even more.

- Learning and development is the master key to success during this crisis times -enable learning as a journey not as a program, with the entire dynamics of working has been changing, learning -forgetting curve is expected to further increase and so attention span of learners /trainees is going to decrease. To increase their attention and retention capacity, organization must design learning models in small parts and multiple touchpoints should be included in the same in stipulated time frame.

- Leverage virtual learning - With increased use of virtual technology, the emergence of virtual learning and e - learning is here to stay and is going to be an unavoidable parts of our lives. With the help of industry experts organizations can ensure having webinars, classroom trainings, virtual coaching for reskilling and upskilling its employees.

- Flexibility - Work from home and hot desking is going to be the new normal.

- Policies and facilities management - frame policies, redesign HR policies handbook, be resilient to changes and adapt it.

- Reward and recognize -In the post Covid world, rewards and recognition needs to become an integral component of employee engagement tailor made REtR program needs attention at this times.

\section{CONCLUSION}

With the help of literature review, various articles has been analyzed and through the present study it can conclude by suggesting some effective ways to boost employee engagement for organization's in these trying times. Research paper also concludes that employees wants to be listened and heard. Organization needs to understand this thing as employees are experiencing a range of concerns about their well-beings and a lot other thing during this grievous times, when management takes effort and listen to its employees concerns it shows that they care about them, pay special attention towards introducing upskilling programs and initiatives that helps them stay productive and feel energetic else they might feel lost and lethargic.

This is the time when organizations can actually take such initiatives because employees will remember how their organization supported them and was there by their side during this crucial time phase. It will reduce attrition rate and helps in creating employer branding too. All the dealing and discussion needed to be revolved around empathy as empathy is going to be the new guiding principle during this unprecedented times. At this very time, HR leaders have an golden opportunity to support their organization with IT solutions, software i.e. Digital technologies. Focus should be laid upon developing effective platforms to configure engagement programs. Building an effective and strong culture helps especially during these times. Sustaining engagement is more important than ever!

\section{REFERENCES}

Chanana N., Sangeeta, Employee Engagement practices during COVID-19 Lockdown, Journal of Public Affairs, 2020

https://axerosolutions.com/blogs/timeisenhauer/ pulse/365/20-fundamental-problems-linked-toemployee-disengagement

https://cultureiq.com/blog/employee-engagementcompany-culture/\# : : text=Employee \% 20 engagement $\% 2 \mathrm{C} \% 20$ while $\% 20$ important $\% 2 \mathrm{C} \% 20$ i s , o f \% 20 a \% 20 s tro n g \% 20 c o m p a n y \% 20 culture.Cttext $=$ The $\% 20$ stronger\%20a\%20company's\%20 culture, and \% 20 committed \%20 to \%20your\% 20 company.

https://decision-wise.com/is-autonomy-important-inyour-job-they-think-so/

https://decision-wise.com/why-perks-dont-result-inemployee-engagement/

https://possibleworks.com/blog/top-5-employeeengagement-trends-post-covid-19/

https://www.engagementmultiplier.com/resources/isyour-team-falling-into-the-covid-trap/

https://www.gartner.com/smarterwithgartner/the9-questions-that-should-be-in-every-employeeengagement-survey/

https://www.google.com/url?sa=tctsource=web\&trct=j Cturl=https://www.quantumworkplace.com/impact-ofcovid-19-on-employee-engagement

https://www.google.com/url?sa=tCtsource=webArct=jAtu $\mathrm{rl}=\mathrm{https}$ //www.statestreet.com/content/dam/statestreet/ documents/Articles/Crisis-as-Catalyst-Leadership-andEmployee-Engagement-COVID-19.PdfAtved=2ahUKEw jXkPTkuevuAhWLbnoKHUJTCFkQFjAAegQIARABCtus $\mathrm{g}=\mathrm{A0vVaw0guaU3vSq84vyczQEzeSqr}$

https://www.leadershipall.com/5-strategies-to-boostemployee-engagement-during-a-crisis/

https://www.peoplemattersglobal.com/amp-employeeengagement-why-engagement-is-the-key-to-growthduring-times-of-uncertainty-27358

https://www.toolbox.com/hr/engagement-retention/ articles/what-is-employee-retention/

https://www2.deloitte.com/mt/en/pages/human-capital/ articles/mt-employee-engagement-and-covid-19.html Kaushik M., Guleria N., The Impact of Pandemic COVID-19 In Workplace, European Journal of Business Management, 2020, 12(15)

Kumar A., Kapoor S., Employee Engagement amidst COVID-19 pandemic: A Challenge or Opportunity for Indian Organisation, International Journal of Advanced Science and Technology, 2020, 29(9), pp. 1980-1987

Saji B.S., Employee Engagement and its Role during Crisis Management: A conceptual Model, European Journal of Business Management, 2014, 16(19)

Setyo Riyanto (2020) Factors affecting employee engagement of state-owned enterprise employees in Indonesia, Journal of Critical Reviews, 7(19), 39393945 